\title{
ANALYSIS OF THE DEMAND FOR PRIVATE HEALTHCARE IN SOUTH AFRICA
}

\author{
Steven Henry DUNGA* \\ North West University, South Africa
}

\begin{abstract}
Access to a good and healthy life is a human right recognised globally. The fight to deal with poverty and food insecurity as the top two sustainable development goals (SDGs) under the global agenda 2030 can only be achieved if a majority of the world population is able to participate in economic activities. However, the provision of healthcare is complicated by the nature of the demand and supply function. There is inefficient provision due to the positive externalities associated with healthcare provision and consequently the social efficiency is not achieved, especially when private provision is considered, and therefore the need for government involvement. This paper analyses the demand for private healthcare in South Africa, using the data collected from a general household survey with a sample of 21601 households. The results of the logistic regression model show that the gender of the head of a household, income, food security status, age of head of household and social grant and pension status were among the significant predictors of demand for private healthcare. The study provides insights on how provision of healthcare should be tailored so as to achieve maximum efficiency in public provision of healthcare.
\end{abstract}

JEL classification: I11, I15, I32, H41

Keywords: households, externalities, demand structure, public goods, mixed goods, healthcare

\section{Introduction and background of healthcare and its demand}

A health and economically productive life is a good foundation for any society. It is pertinent in order to deal with the global issues of poverty inequality and unemployment. Each and every country strives to have a health workforce in

\footnotetext{
* Corresponding author. Address: North West University, South Africa, P. O. Box 1174, Vanderbijlpark, Phone: +27 169103372, Email: Steve.dunga@nwu.ac.za, https://orcid.org/0000-0002-0911-144X, Email: j.samul@pb.edu.pl
} 
order to have maximum utilisation of the skills that are available through human capital investments. The need to have a proper efficient and non-discriminatory health care system is therefore an integral part of dealing with the global problem of poverty and low growth. Different countries have policies aimed at providing good healthcare to their citizens. World over, the issues of access and affordability are paramount.

The Constitution of the Republic of South Africa stipulates in chapter 2 section 27 (1) that, access to healthcare is a human right and should be available to every person (Bill of rights, 1996). Therefore, the provision of healthcare falls under those services that need to be provided by government. The fact that healthcare is not provided only by government, but also the private sector makes healthcare's supply and demand unique. Healthcare is not a straightforward private good; it is associated with a number of unique features. The fact that a number of countries have had varied experiences in the provision or establishment of an efficient system is testimony to the uniqueness of the service (Asteraye, 2002; Gubb, James, Meller-Herbert, 2009; Hernandez, Suglia, 2016; Owusu-Sekyere, Chiaraah, 2014; World Bank, 1992).

Van Eeden (2009) identified three characteristics of the demand for healthcare. Firstly, it is a derived demand, meaning that individuals or households do not consume or demand healthcare primarily for the utility gained from directly consuming healthcare services or products. Derived demand entails that the utility or the satisfaction is derived from what comes after the product or service is consumed. Therefore, derived demand entails that what is needed is beyond the service. A similar example is demand for education, which is also a derived demand. Therefore, people demand healthcare for the perceived benefits in terms of their general health status (van Eeden, 2009). In the theoretical literature, this aspect of the demand for healthcare is usually linked to Grossman's demand for healthcare model where health demand is derived as both an investment and consumption expenditure. As will be discussed in detail in the literature review, Grossman argues that health is produced by the consumption of health inputs in the production of healthy days. Another unique characteristic of the demand for healthcare is that it is associated with excess demand. Most goods or services that have positive externalities are characterised by excess demand, as the private cost is usually much less than the social benefit, which includes the unintended positive externalities. Thirdly, there is supply-induced demand for healthcare. The absences of health may be associated with negative externalities. The market for healthcare is therefore different from the market of pure public goods or that of private goods. A private good or service is one that has both rivalry and is excludable, while a pure public good is both non-rival and non-excludable.

Beyond these characteristics of health demand, the demand for healthcare is affected by the same determinants that other private products have, especially when considered broadly at a household level (Asteraye, 2002; World Bank, 1992). A household that has health insurance coverage has to make a decision as to what the opportunity costs are in buying this health insurance. Therefore, the basic determinants of demand such as the price of the product, price of substitutes and complements, income and other demographic factors become important. These will be revisited in the research methods section when specifying the empirical model. 
This paper, however, makes a bold statement that healthcare demand in South Africa is affected by the inequality nature of the country and consequently has become unaffordable to those who should ordinarily be able to afford it. This has been made possible by the availability of a bourgeoisie class of people at the very top who have accepted a very high premium for health insurance because they can afford it, and therefore the private health sector only serves a few at the expense of the overburdened public health system. It is the hypothesis of this paper that although in normal circumstance demand for health would be higher on female-headed households, being the case that mostly men are the ones that have access to higher levels of income, it will be likely that in South Africa the demand for private health care will be more on the male-headed households whose probability of being in employment is higher than female-headed households.

\section{Literature review}

The literature on the demand function for healthcare is similar to a large extent to that of demand for other semi-public goods such as education. Health is linked to a number of other valuable aspects of life that are not possible in the absence of good health (Asteraye, 2002). It is also considered a public good in the sense that it has higher levels of external effects. The externalities of health as a product can be both positive and negative (Goodman, Marin, 1998). Positive externalities are associated with good health and negative externalities are associated with the absence of good health. Ebola (Mehtar, 2018) is an example of negative externalities associated with poor health, and efficient labour force or flu prevention due to a flu vaccination are examples of positive externalities of good health (Blavin, Ramos, Lallemand,, Fass, 2017).

According to the World Bank (1992) in the understanding and formulation of healthcare functions, two alternative models for describing the way individuals or economic units make choices regarding health care utilisation and related decisions are used. Firstly, a basic approach is to treat health as one of the several commodities over which individuals have well-defined individual preferences, and therefore can be understood under the ordinary determinants of demand. A second approach used in the analysis of healthcare choices is to use an intertemporal model of consumption decisions and to treat health as a stock variable within a human capital framework (World Bank, 1992). Healthcare use can certainly have long-lasting effects, and the idea of healthcare representing an investment in health has been popular at least since the World Bank's 1993 World Development Report. When health is considered as an investment, then only those with the required capital to access inputs in the production of this health are able to have better health than those who cannot afford the investment. It is in the line of such thinking that the provision of healthcare is no longer in line with the constitution, which provides for access to health for all people.

\subsection{Heath, income and income inequality}

There is a simultaneous relationship between health and income. Those who have higher levels of income are able to access good healthcare, whereas those with low income depend on public health services, which, in many cases, are 
of low quality, especially in developing countries. In what is known as the spirit level report by Wilkinson and Pickett (2009), it was put to the fore that income inequality was central to health; it is argued that inequality caused a large array of health and social problems, which affected everyone in society, not just those at the bottom (Rowlingson, 2011). The high level of income inequality has affected the health sector in a unique way in South Africa. Private healthcare or health insurance in South Africa is so expensive that it excludes the average person from coverage, and, in turn, the public sector has had to deal with a higher than normal demand due to the absence of affordable insurance for those with modest incomes.

\subsection{Health and gender}

There is a strong link between gender and health. Firstly, it is assumed that women tend to mind more of their health than men, but also because women are associated with child birth and child care at a higher level than men (Fikree, Pasha, 2004). In reality, women face more health challenges beyond their control, for example, Fikree and Pasha (2004) point out that by their nature, reproductive health hazards are borne by women alone and this in most cultures is not a choice. They further argue that poor outcomes for both mother and child are inevitable. There are a number of studies that have shown the link between gender and health and how there is a need to focus on the different dynamics, not essentially about women's health, but rather the interactions between gender and heath (Cameron, Song, Mnaheim, Dunlop, 2010, Doke, 2015, HLEG, 2010). In the United States of America, one of the debates around the Affordable Care Act, also known as Obamacare, was the issue of pre-existing conditions; and also that women were made to pay more by the mere fact that they were women and the Obamacare was to deal with those discriminatory clauses. There seem to be a significant link between healthcare demand and gender (Cameron et al., 2010).

\subsection{Health and poverty}

Poverty remains an important issue in almost all sectors of public discourse. The WHO (2013) argued that the poor suffer worse health and die younger. They also pointed out that the poor have higher than average child and maternal mortality, higher levels of disease, more limited access to healthcare and social protection, and gender inequality further disadvantages the health of poor women and girls (WHO, 2013). Wherever public expenditures are increasing, there is an intrinsic understanding that it will impact on the lives of the poor. Therefore, the introduction or intention to introduce a national health insurance is mainly premised on the understanding that there are too many citizens who are relying on public healthcare and yet the private sector could offer relief. This then is the link between poverty and health; the relationship is simultaneous, meaning that there is causality from lack of health to poverty or poverty to poor health (Grant, 2008; Ngoma, Mayimbo, 2017, Phipps, 2003, Price, Khubchandani, Webb, 2018). Households that are poor are more likely to have poor health due to the many attributes that are associated with poverty that may lead to less consumption of 
health services, especially the private ones that require payment. On the other hand, poor health may also lead to poverty in the sense that people who are not physically fit are less likely to have a stable job or any source of income, and therefore are more likely to fall into the poverty trap.

The paper therefore attempts to bring to the fore the understanding that health provision that excluded the majority erodes the gains made by the few that are included due to the externality attributes associated with healthcare. There is also a deliberate attempt to show that there are consequences associated with health care, positive for good healthcare both at individual and societal level and negative for poor health, also both at individual and societal level.

\section{Research method and data}

In this paper, a deliberate attempt is made to distinguish research methods from research methodology. In most papers and postgraduate research, there is an acceptance in referring to research methods as research methodology. However, the two are fundamentally different in that research methods only present the steps followed in the data collection preparation and analysis, as opposed to research methodology, which is a study of research methods (Rajasekar, Philominathan, Chinnathambi, 2006, Walliman, 2011). Therefore, in this section, we present research methods and not methodology. The positivist paradigm of testing hypothesis with an objective as opposed to subjective approach and consequently testing hypothesis using quantitative data was used in the paper. The main objective, as discussed in the preceding sections, was to test which household and household head characteristics are significant in explaining the demand for private healthcare, with a special focus placed on the gender of the head of household.

The paper used data that was collected by Statistics South Africa in a General Household Survey (GHS). The study was conducted from January to December of 2016 and the data was made available on line on datafirst, published in 2017. The data has 21601 households that were involved in the survey. These households were sampled across the country in an effort to have a representative sample. According to Statistics SA (2017), the target population of the survey consists of all private households in all nine provinces of South Africa and residents in workers' hostels. The survey does not cover other collective living quarters such as students' hostels, old-age homes, hospitals, prisons and military barracks, and is therefore only representative of non-institutionalised and non-military persons or households in South Africa (Statistics SA, 2017).

The demand for private healthcare was represented by where the household went for help when they were sick. Table 1 presents the frequencies of the responses. Based on these responses, a binary dependent variable was calculated. 
Table 1. Source of medical help

\begin{tabular}{llll}
\hline Source of help & Frequency & Percent & $\begin{array}{l}\text { Cumulative } \\
\text { percent }\end{array}$ \\
\hline Hospital & 1674 & 7.7 & 7.7 \\
Clinic & 14044 & 65.0 & 72.8 \\
Other & 115 & .5 & 73.3 \\
Hospital & 430 & 2.0 & 75.3 \\
Clinic & 332 & 1.5 & 76.8 \\
Private doctor/specialist & 4632 & 21.4 & 98.3 \\
Traditional healer & 100 & .5 & 98.7 \\
Spiritual healers & 35 & .2 & 98.9 \\
Pharmacy/chemist & 83 & .4 & 99.3 \\
Health facility provided by employer & 52 & .2 & 99.5 \\
Alternative medicine, e.g. & 2 & .0 & 99.5 \\
homoeopathist & & & \\
Other in private sector & 10 & .0 & 99.6 \\
Do not know & 4 & .0 & 99.6 \\
Unspecified & 88 & .4 & 100.0 \\
Total & $\mathbf{2 1 6 0 1}$ & $\mathbf{1 0 0 . 0}$ & \\
\hline Source: Authors'calculations from & &
\end{tabular}

Source: Authors' calculations from the GHS data

Therefore, those who indicated getting help from private doctors and also those who went to other private sectors were categorised together as demanding private healthcare; the rest of the responses were categorised as not demanding private healthcare, and thereby relying on public healthcare services or otherwise. Table 2 therefore presents a frequency distribution of the binary variable, which will be used as a dependent variable in the model. The results in Table 2 show that $21.5 \%$ of the households in the sample demand private healthcare, while the majority of the households in the sample, accounting for $78.5 \%$, did not demand or did not have private health coverage.

Table 2. Frequency distribution of demand for private health services

\begin{tabular}{llll}
\hline Health demand & Frequency & Percent & $\begin{array}{l}\text { Cumulative } \\
\text { percent }\end{array}$ \\
\hline $\begin{array}{l}\text { No private health } \\
\text { demand }\end{array}$ & 16959 & 78.5 & 78.5 \\
$\begin{array}{l}\text { Demand private } \\
\text { health services }\end{array}$ & 4642 & 21.5 & 100.0 \\
\begin{tabular}{l} 
Total \\
\hline
\end{tabular} & 21601 & 100.0 & \\
\hline
\end{tabular}

Source: Authors' calculations from the GHS data 


\subsection{Model specification}

Based on the nature of the dependent variable, a conditional probability model needs to be used in a regression analysis. As the dependent variable is a two-category without need for ranking, a binary logistic model is appropriate. The binary logistic model estimated in this paper uses the maximum likelihood estimation. Logistic regression is the appropriate model when using a dependent variable of a categorical outcome. For categorical variables, it is inappropriate to use linear regression because the response values are not measured on a ratio scale and the error terms are not normally distributed (Czepiel, n.d.). The logistic regression model equates the logit and transforms the log-odds of the probability of a success, to the linear component. Therefore, the mathematical equation of the logistic regression model is specified as follows;

$$
\log \left(\frac{\pi_{i}}{1-\pi_{i}}\right)=\sum_{k=0}^{K} x_{i k} \beta_{k} \quad i=1,2, \ldots, N
$$

Consequently, equation 1 is done with maximum likelihood estimation, which entails finding the set of parameters for which the probability of the observed data is greatest.

In logistic regression, a complex formula is required to convert back and forth from the logistic equation to the OLS-type equation. The logistic formulas are stated in terms of the probability that $Y=1$, which is referred to as $\hat{p}$. The probability that $Y$ is 0 is $1-\hat{p}$. Where $Y=1$ is the probability that the household has private healthcare coverage and $Y=0$ means that the household does not have private health insurance or coverage.

$$
\ln \left(\frac{f}{1-p^{p}}\right)=\beta_{0}+\beta_{1} X \quad \ldots
$$

From equation 2, we can calculate the expected probability that $Y=1$ for given values of $X$ as follows

$$
\hat{p}=\frac{\exp \left(B_{0}+B_{1} X\right)}{1+\exp \left(B_{0}+B_{1} x\right)}=\frac{e^{B_{0}+B_{1} x}}{1+e^{B_{0}+B_{1} x}}
$$

Therefore, with the variables that are used in the model for the determinants of demand for private healthcare, the model to be estimated will be simply expressed as follows:

$$
\ln \left(\frac{p}{1-p}\right)=\beta_{0}+\sum_{i}^{n} \emptyset_{i}+\sum_{j}^{n} \theta_{j}+\varepsilon \ldots
$$

Where $\sum_{i}^{n} \emptyset_{i}$ represents all the factors in the models and $\sum_{j}^{n} \theta_{j}$ represents the covariates in the model.

If $n\left(\frac{p}{1-f}\right)$ is substituted by $Z$, then the familiar presentation of the model becomes 


\section{Results and discussion}

The presentation of the results and the discussion thereof start with the explanation of the variables and the descriptive statistics of the variables in the model. The dependent variable has already been presented in Table 2. Table 3 presents the frequency distribution of gender of head of households in the sample. This is relevant in the sense that the study focuses on the gender disparity between male and female heads of households, to investigate whether there are changes taking place with regard to access to income and employment that may proxy the ability to afford private healthcare. Table 3 shows that there were $41.7 \%$ female headed households, and $58.3 \%$ were male-headed households.

Table 3. Gender of the head of household

\begin{tabular}{|c|c|c|c|}
\hline Gender & Frequency & Percent & $\begin{array}{l}\text { Cumulative } \\
\text { percent }\end{array}$ \\
\hline $\begin{array}{l}\text { Female head of } \\
\text { household }\end{array}$ & 9009 & 41.7 & 41.7 \\
\hline $\begin{array}{l}\text { Male head of } \\
\text { household }\end{array}$ & 12592 & 58.3 & 100 \\
\hline Total & 21601 & 100.0 & \\
\hline
\end{tabular}

Source: Authors calculations from the GHS data

Gender was entered as a dummy variable in the model with females coded as 1 and males coded as 0 , meaning that the coefficient represented the female headed households. Other variables in the model include household total income, which was transformed to natural logs; food security, which was measured as a scale, the higher the score the higher the probability of being food insecure, and the lower the score the lower the probability of being food insecure. Household size was also used in the model. Pension was another variable of interest, which was also entered as a dummy variable. Table 4 presents the coding of the categorical variables in the model.

Table 4. Categorical variable coding

\begin{tabular}{l|lll}
\hline Grants & Yes & $\mathbf{1 0 8 4 5}$ & $\mathbf{1 . 0 0 0}$ \\
& No & 10411 & .000 \\
Pensions & Yes & 953 & 1.000 \\
\multirow{2}{*}{ Salaries/wages/commission } & No & 20303 & .000 \\
& Yes & 13520 & 1.000 \\
\multirow{2}{*}{ Gender head of household } & No & 7736 & .000 \\
& Female & 8904 & 1.000 \\
& Male & 12352 & .000 \\
\hline
\end{tabular}

Source: Authors' calculations from the GHS data 
Therefore, the interpretation of the results of the regression model follows the normal understanding of a dummy variable, where the category of the variable coded 1 takes the coefficient and is interpreted in relation to the category coded 0 .

\subsection{Results of the logistic regression model}

The results of the logistic regression model are presented in Table 5. The omnibus test had a p-value of 0.000 showing that the model is a good fit. The dependent variable was defined as 1 for having private healthcare coverage, or indicating the demand for private health services. Gender of the head of household was entered in the model as 1 for females. The coefficient for gender in the regression results is negative, which means that males have a higher probability of having private health coverage compared to females. The p-value for gender is 0.000 , which means gender is a significant predictor of the probability of having private health insurance.

Table 5. Logistic regression results

\begin{tabular}{|c|c|c|c|c|c|c|}
\hline Variables & B & S.E. & Wald & $\begin{array}{l}d \\
f\end{array}$ & Sig. & $\begin{array}{l}\text { Exp( } \\
\text { B) }\end{array}$ \\
\hline $\begin{array}{l}\text { Gender head of } \\
\text { household(1) }\end{array}$ & -.178 & .042 & 18.425 & 1 & .000 & .837 \\
\hline Food insecurity & -.698 & .045 & 243.484 & 1 & .000 & .497 \\
\hline Log of income & .194 & .008 & 612.613 & 1 & .000 & 1.214 \\
\hline $\begin{array}{l}\text { House hold size } \\
\text { categorised }\end{array}$ & -.025 & .032 & .637 & 1 & .425 & .975 \\
\hline Pensions(1) & 1.168 & .080 & 214.905 & 1 & .000 & 3.216 \\
\hline $\begin{array}{l}\text { Salaries/wages/commissi } \\
\text { on(1) }\end{array}$ & .708 & .049 & 208.890 & 1 & .000 & 2.030 \\
\hline Age of household head & .017 & .001 & 141.883 & 1 & .000 & 1.018 \\
\hline Grants(1) & - & .054 & 759.213 & 1 & .000 & .224 \\
\hline Constant & - & .121 & 593.829 & 1 & .000 & .052 \\
\hline
\end{tabular}

Dependent variable, $1=$ having health insurance coverage $0=$ no health insurance *Significant at $10 \%{ }^{* *}$ Significant at $5 \%$ *** Significant at $1 \%$

Food insecurity is important as it depicts the availability of other necessities beyond private health. A score was used for food security, with a higher score implying insecure, and a lower score implying food secure. The negative coefficient in the model therefore means that food insecure households have a lower chance of having private health insurance as opposed to the food secure households. The p-value for food insecurity as a predictor was also 0.000 , which is significant at $1 \%$ meaning that food insecurity status is a statistically significant predictor of the probability of a household demanding private healthcare. Therefore, food and health can be competing needs on poor households, just like food was also found to compete with housing in a study on similar households in South Africa (Dunga, Grobler, 2017). 
Income, which was transformed to natural log, shows a positive relationship with the probability of having private healthcare. The positive coefficient means that the higher the total income of the household, the higher the probability of that household demanding private health insurance. The p-value was 0.000 , which is less than 0.01 for the $1 \%$ significance level. Therefore, as expected income is a significant predictor of demand for private health. This is in agreement with a number of studies that have also found a positive correlation between health and income (Mutyambizi, 2008; Owusu-Sekyere, Chiaraah, 2014; n.d.).

The P-value for household size was 0.425 , which is higher than 0.05 or 0.1 for the $5 \%$ and $10 \%$ significance levels, respectively. It therefore means that the size of the household was not a statistically significant predictor of private healthcare demand in the model.

People who are currently receiving pension are those who were previously employed and consequently have managed to accumulate savings; also, those on pension are usually older. The categorical variable for pension was defined as 1 for those on pension and 0 for those not on pension. The coefficient is positive with a significant $p$-value of 0.000 . This means that having pension is a significant predictor of the probability of demanding private healthcare. Also linked to employment were those who indicated that they were on a salary or wages compared to those who were not. The coefficient is positive with a p-value of 0.000 , indicating that having a job was a statistically significant predictor of the demand for private health demand. Therefore, those without a formal income source were most likely to depend on public health services.

Age of the head of household was positively and statistically significant with a $p$-value of 0.000 , implying that older people demanded private healthcare more than the younger heads of households. This may be an indication of youth unemployment, since the younger heads of households comprise those who can be categorised as youth.

Lastly, the model also investigated those on social grants. The negative coefficient for social grants means that those on social grants are less likely to demand private health as opposed to those who are not on social grants. This is an expected outcome, since social grants target people who are considered poor. Therefore, it would be unexpected to find the poor demanding private health insurance. The $p$-value for the social grants variable was also significant at the $1 \%$ level of significance.

\section{Conclusion}

The study has revealed that the majority of households in the South Africa are relying on the public health sector, with $21.5 \%$ of the households in the sample having health insurance and being able to demand services from the private health sector. Gender of head of household was given special attention to test the hypothesis that women are more responsive to health issues and hence are more likely to demand private healthcare. The results showed that demand for private healthcare depended more on other factors such as income and employment, and that male-headed households were found to be more likely to demand private healthcare than females do; this was mainly because male heads of households were more likely to have a job than female heads of household. 
Among the statistically significant determinants was the availability of employment that was represented by salaries or wages. People without a job were the ones who did not demand private health insurance. The most important lesson also coming out of the model was that these were mostly the young heads of household as the age variable showed that the older people were more likely to demand private healthcare than the young heads of household did.

Therefore, besides the fact that private healthcare is expensive, there is a need for the country to continue with the efforts of growing the economy and creating more jobs for the youth. Jobs for the youth will mean an increase in the demand for private healthcare from the youth, which may reduce the strain on the public sector. It may also mean a reduction on the number of people on social grants who are the same people that are also failing to demand private healthcare. Also linked to jobs is pension, and therefore the more people have access to jobs the better for the future as well, since these people will be able to pay for their health insurance after they retire and move on to receiving pension. This paper proposes a more in-depth analysis of the healthcare demand by looking at the provincial difference and also differences by education level. Also, a focus is needed on the cost of health insurance and a possibility of coverage that could be tailored to people's financial capabilities.

\section{References}

Asteraye, N. (2002). Determinants of Demand for Health Care Services and their Implication on Health Care Financing: The Case of Bure Town, XI(1), 87-122.

Blavin, F., Ramos, C., Lallemand, N. C., Fass, J. (2017). Analyzing the Public Benefit Attributable to Interoperable Health Information Exchange.

Cameron, K., Song, J., Mnaheim, L., Dunlop, D. (2010). Gender Disparities in Health and Healthcare Use. Journal Of Womens Health, 19(9).

Czepiel, S. A. (n.d.). Maximum Likelihood Estimation of Logistic Regression Models : Theory and Implementation.

Doke, P. P. (2015). Gender issues in health sector. Journal of Krishna Institute of Medical Sciences University, 4(2), 10-18.

Dunga, S. H., Grobler, W. (2017). The Nexus of Food and Housing Insecurity in South. International Journal of Social Sciences and Humanity Studies, 9(2), 95108.

Fikree, F. F., Pasha, O. (2004). Role of gender in health disparity: the South Asian context. Bmj, 328(7443), 823-826. https://doi.org/10.1136/bmj.328.7443.823

Goodman, A. C., Marin, S. (1998). HMOs and Health Externalities: A Local Public Good Perspective (August).

Grant, U. (2008). Health and Poverty Linkages: Perspectives of the chronically poor. Chronic Poverty Research Centre (February 2005).

Gubb James Meller-Herbert, O. (2009). Markets in health The theory behind the policy (December), 1-69.

Hernandez, D., Suglia, S. (2016). Leveraging the Social Determinants to Build a Culture of Health Housing as a Social Determinant of Health. Retrieved from https://healthequity.globalpolicysolutions.org/wp-content/uploads/ 2016/12/Housing2.pdf 
HLEG. (2010). Gender and Health. High Level Expert Group Report on Universal Health Coverage for India, 295-300.

Mehtar, S. (2018). Guide to Infection Control in the Hospital. In international society for infectious diseases.

Mutyambizi, V. (2008). Country Case Study Health Insurance in South Africa. Health Economics Unit, Iniversity of Cape Town, 11.

Ngoma, C., Mayimbo, S. (2017). The Negative Impact of Poverty on the Health of Women and Children. Annals of Medical and Health Sciences Research, 7, 442-446.

Owusu-Sekyere, E., Chiaraah, A. (2014). Demand for Health Insurance in Ghana: What Factors Influence Enrollment? American Journal of Public Health Research, 2(1), 27-35. https://doi.org/10.12691/ajphr-2-1-6

Phipps, S. (2003). The Impact of Poverty on Health. CPHiSPC, (June).

Poor people' s experience of health and ill-health Foreword. (n.d.).

Price, J., Khubchandani, J., Webb, F. J. (2018). Poverty and Health Disparities: What Can Public Health Professionals Do? Health Promotions Practice, (March). https://doi.org/10.1177/1524839918755143

Rajasekar, S., Philominathan, P., Chinnathambi, V. (2006). Research Methodology, $1-$ 53. https://doi.org/arXiv:physics/0601009v3

Rowlingson, K. (2011). Does income inequality cause health and social problems? Joseph Rowntree Foundation, (September).

Statistics SA. (2017). General Household Survey. Statistical Release P0318, 21(4), 482. https://doi.org/10.1016/S0022-5223(12)00629-0

WALLIMAN, N. (2011). Research Methods (1st ed.). New York: Routledge.

WHO. (2013). DAC Guidelines and reference Series: Poverty and Health.

World Bank. (1992). The Demand for Health Care Services. Microeconomics of Healthcare and Insurance Markets, 55-90. 